\title{
Produção urbana no semiárido brasileiro: um estudo sobre Pau dos Ferros, RN, Brasil
}

\author{
Urban production in the brazilian semi-arid: a study about Pau dos Ferros, \\ RN, Brazil \\ Producción urbana en el semiárido brasileño: un estudio sobre Pau dos Ferros, \\ RN, Brasil
}

\author{
Carla Caroline Alves Carvalho ${ }^{1}$ \\ Larissa da Silva Ferreira Alves ${ }^{1}$ \\ Almir Mariano de Sousa Junior ${ }^{2}$ \\ Francisco do O de Lima Junior ${ }^{3}$
}

\begin{abstract}
Recebido em 23/02/2018; revisado e aprovado em 10/05/2018; aceito em 06/06/2018
\end{abstract}
DOI: http://dx.doi.org/10.20435/inter.v0i0.1855

\begin{abstract}
Resumo: Esta pesquisa objetiva analisar aspectos da morfologia urbana da cidade de Pau dos Ferros, localizada no interior semiárido do Rio Grande do Norte, tomando por base a atuação de agentes produtores do espaço. Enquanto procedimentos metodológicos, foram desenvolvidas: revisão bibliográfica, visitas in loco e análise documental. Concluiu-se que a lógica de acumulação capital pauta a produção desses espaços, contribuindo para a valorização imobiliária e para a segregação socioespacial na cidade.
\end{abstract}

Palavras-chave: produção do espaço urbano; valorização fundiária; Pau dos Ferros, RN.

Abstract: This research aims to analyze aspects of the urban morphology of the city of Pau dos Ferros, located in the semi- arid interior of Rio Grande do Norte, based on the performance of agents that produce space. Methodological procedures were developed: bibliographic review, on-site visits and documentary analysis. It was concluded that the logic of capital accumulation guides the production of these spaces, contributing to the real estate valuation and the socio-spatial segregation in the city.

Keyworks: production of urban space; land valuation; Pau dos Ferros, RN.

Resumen: Esta investigación objetiva analizar aspectos de la morfología urbana de la ciudad de Pau dos Ferros, ubicada en el interior semiárido de Rio Grande do Norte, tomando como base la actuación de agentes productores del espacio. En cuanto procedimientos metodológicos, fueron desarrolladas: revisión bibliográfica, visitas in situ y análisis documental. Se concluyó que la lógica de acumulación capital pauta la producción de esos espacios, contribuyendo para la valorización inmobiliaria y para la segregación socioespacial en la ciudad.

Palabras clave: producción del espacio urbano; valorización de la tierra; Pau dos Ferros, RN.

\section{INTRODUÇÃO}

No ínterim de heterogeneidades que permeiam as redes urbana do Brasil, desde suas primeiras ocupações, o ordenamento territorial (OT) dado às cidades brasileiras foi sendo moldado de maneira a conter muitas contradições no tecido urbano, que são refletidas nas elevadas desigualdades sociais, na segregação socioespacial, degradação ambiental, dentre outras problemáticas urbanas. Para dar encaminhamentos a tal vereda de pesquisa, parte-se do pressuposto de que a contradição é um aspecto intrínseco ao sistema capitalista e, consequentemente, reforça o bojo da formação da cidade (CARLOS, 2015).

\footnotetext{
${ }^{1}$ Universidade do Estado do Rio Grande do Norte (UERN), Campus Avançado "Profa. Maria Elisa de A. Maia", Pau dos Ferros, Rio Grande do Norte, Brasil.

${ }^{2}$ Universidade Federal Rural do Semi-Árido (UFERSA), Pau dos Ferros, Rio Grande do Norte, Brasil.

${ }^{3}$ Universidade Regional do Cariri (URCA), Crato, Ceará, Brasil.
} 
A expansão do perímetro urbano da cidade provoca muitas modificações sobre os espaços rurais, que possuem características próprias, modo de vida e relações econômicas diferenciadas. Abellán (2015) destaca que, nas últimas décadas, ocorreram muitas modificações nas tradicionais morfologias e hierarquias urbanas, que implicaram transformações no entorno das cidades médias. Em consequência desse processo, são geradas, ao longo do território, diferentes áreas periurbanas, retratadas como sendo um espaço de transição, resultado da relação entre campo e cidade, que comportam franjas de níveis decrescentes de ocupação do solo (ALEGRE, 2016). Nesses espaços, há a presença simultânea de atividades características tanto da cidade quanto do campo, comportando uma população proveniente do êxodo rural e do meio urbano.

Vale ressaltar que outra forma de entender o espaço periurbano, conforme destacam Alves e Vale (2013), é tomá-lo como sendo um espaço vazio, que está reservado para a ação especulativa do solo, caracterizando assim a "estocagem" para venda em momento mais oportuno. Isso evidencia, na produção da cidade, a contradição do valor de uso e do valor de troca, tornando-se mercadoria, como todos os produtos do trabalho humano (CARLOS, 2015). Essa realidade pode ser justificada mediante a perspectiva de que, na produção do espaço urbano, exista disputa de interesses de diferentes agentes sociais, notoriamente elencados por Corrêa (1989) como sendo: proprietários dos meios de produção, dando destaque aos responsáveis pelo setor industrial; os proprietários fundiários; os promotores imobiliários; o Estado; e os grupos sociais excluídos.

É importante observar também que as contradições e ações desses agentes estão presentes nas cidades de grande, médio ou de pequeno porte, variando apenas os níveis de complexidade e de percepção. Dessa maneiro, o estudo acerca da contribuição de cada autor é importante para o entendimento do processo de urbanização e a existência de áreas periurbanas. Nesse contexto, pode-se destacar a cidade de Pau dos Ferros, que está localizada no interior do Rio Grande do Norte e passa por muitas modificações em sua morfologia urbana mediante a ação de diferentes agentes. Dentro da cidade, os bairros São Geraldo e do Chico Cajá são exemplos dessa heterogeneidade, devido a estarem localizados em distintas zonas de expansão urbana da cidade, mantendo padrões que ora são similares, ora se diferenciam no processo de constituição da mancha urbana pauferrense.

Logo, esta pesquisa tem como objetivo analisar aspectos da morfologia urbana da cidade de Pau dos Ferros, localizada no interior semiárido do Rio Grande do Norte, tomando por base a atuação de agentes produtores do espaço.

Para tanto, esta pesquisa se organiza em três seções, além da introdução apresentada. A primeira retrata a metodologia adotada, evidenciando o método, os instrumentos metodológicos e uma caracterização da área de estudo. Em seguida, se apresentam os resultados encontrados, analisando as contribuições dos diferentes agentes produtores do espaço. Posteriormente, estão as considerações finais e as referências bibliográficas.

\section{METODOLOGIA}

No intuito e alcançar o objetivo traçado, foi desenvolvida a revisão bibliográfica para melhor respaldo às discussões e entendimento da realidade em análise. Assim, os principais autores utilizados foram: Abellán (2015), para o entendimento de cidade dispersa; Alegre (2016) e Alves e Vale (2013), na discussão acerca de periurbanização; o estudo da produção capitalista do espaço e suas segregações foi embasado principalmente por Carlos (2015) e Maricato (2013); no 
tocante aos agentes produtores do espaço urbano, tomou-se como referência Corrêa (1989) e, quanto ao direito à cidade, se fez uso das ideias de Harvey (2013).

Além disso, foram feitas visitas in loco no intuito de realizar levantamento fotográfico e percepção da realidade do objeto de estudo. Buscou-se, também, dados sobre o processo de formação urbana da cidade, especificando dois bairros de expansão urbana, Chico Cajá e São Geraldo a partir de análises do registro de loteamentos e demais dados de consulta pública na Secretaria Municipal de Tributação de Pau dos Ferros-RN-Brasil. A abordagem desses dados se deu por meio de estatística descritiva elaborada com base nos dados de área de lote, área construída, ocupação do lote contidos nos registros da Secretaria Municipal de Tributação de Pau dos Ferros, RN, Brasil. Essas informações foram utilizadas para a verificação da área média do lote, área média construída, quantidade de lotes ocupados e de terrenos vazios, bem como do valor venal ${ }^{4}$ médio dos terrenos e imóveis de cada bairro, com o intuito de perceber os processos de ocupação, valorização fundiária, e tendências de expansão urbana. Vale ressaltar ainda que foi utilizado o Google Earth como ferramenta da geotecnologia para a elaboração de mapas capazes de representar graficamente a ocupação das áreas em estudo.

\subsection{Caracterização do objeto de estudo}

Este estudo é pautado na análise da cidade de Pau dos Ferros, localizada no extremo oeste do estado do Rio Grande do Norte, Brasil, conforme mostra a Figura 1.

Figura 1 - Localização do município de Pau dos Ferros no Estado do Rio Grande do Norte, Brasil

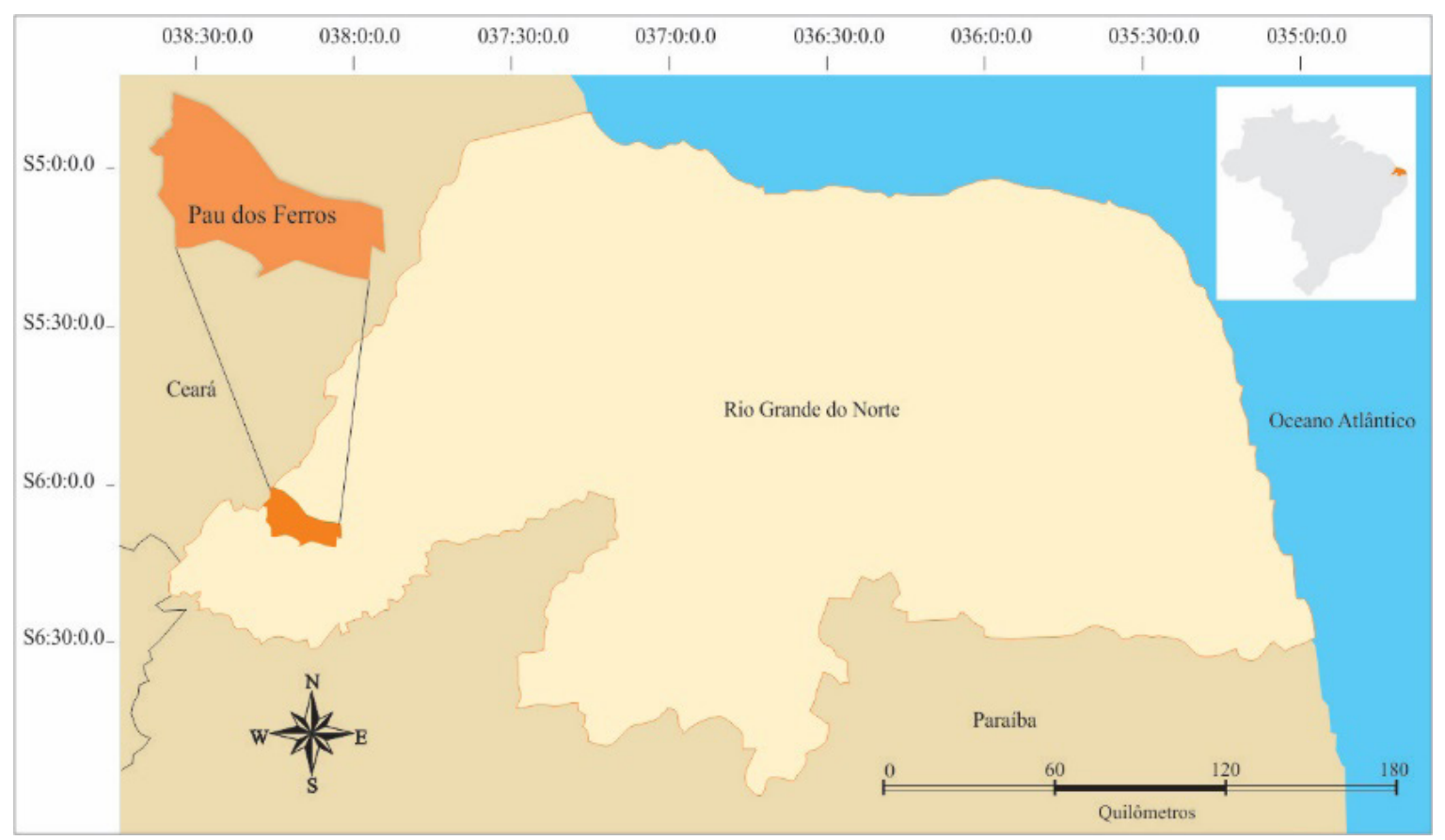

Fonte: Elaboração gráfica própria (2018), a partir de dados do Instituto Brasileiro de Geografia e Estatística (IBGE, 2010).

\footnotetext{
${ }^{4}$ De acordo com o Art. 42 da Lei Complementar 05/2010, que aprova o Código Tributário de Pau dos Ferros e dá outras providências, o valor venal é a base de cálculo para o Imposto sobre a Propriedade Predial e Territorial Urbana (IPTU) é calculado com base no valor venal do imóvel. Esse valor é estipulado pelo Poder Executivo Municipal toma como referência diversas características que podem valorizar ou desvalorizar o imóvel, como a área construída, a localização, a situação de uso, o valor do m², entre outras (PAU DOS FERROS, 2010).
} 
Pau dos Ferros é caracterizada como uma pequena cidade face ao seu pequeno quantitativo populacional, no entanto exerce funções de cidade média pela capacidade polarizadora da região na qual está inserida, a Região do Alto Oeste Potiguar (DANTAS, 2014). As heterogeneidades que marcam o tecido urbano dessa cidade estão representadas em sua morfologia, que, por sua vez, reflete a formação, dinâmica e expansão urbana de Pau dos Ferros, notadamente percebida nos bairros Chico Cajá e São Geraldo.

Para o contexto da cidade em estudo, os proprietários dos meios de produção não exercem influências tão perceptíveis quanto os demais agentes. Isso porque a centralidade urbano-regional da cidade se caracteriza principalmente por ser um polo prestador de serviços, e não polo industrial, assim como muitas cidades médias do semiárido (DANTAS, 2014).

Na expansão urbana de Pau dos Ferros, há uma forte presença do contínuo desmembramento de propriedades privadas, antes consideradas como rurais, para a abertura loteamentos espalhados de maneira heterogênea ao longo da cidade e nas zonas de crescimento do perímetro urbano. Isso caracteriza a ação dos proprietários fundiários que vendem áreas tradicionalmente rurais para a instalação de atividades urbanas, aumentando assim os limites físicos do perímetro urbano sobre o campo, conforme mostra a Figura 2, que evidencia a mancha de expansão urbana.

Figura 2 - Expansão urbana de Pau dos Ferros entre 2007-2014

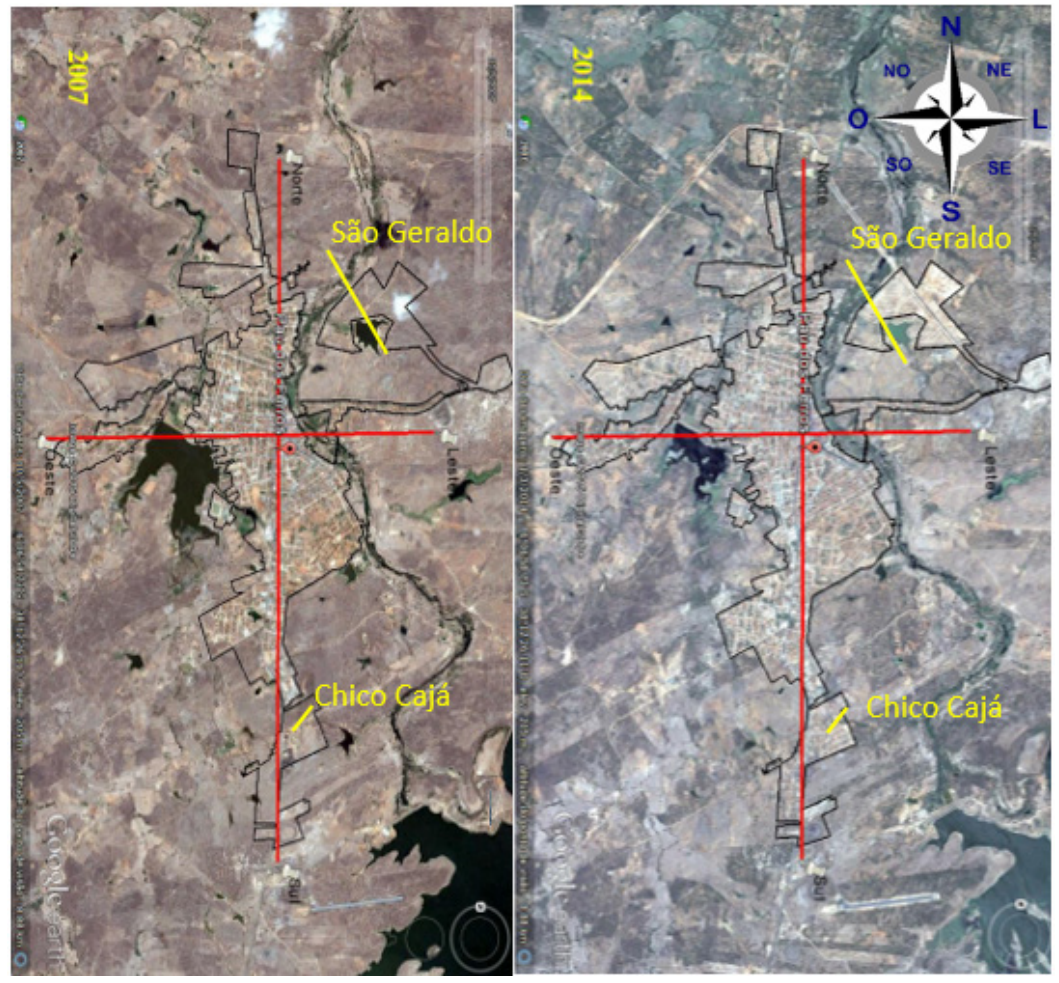

Fonte: Adaptado de Lima (2015).

A leitura da Figura 02 permite observar que houve um crescimento da cidade em todas as direções, havendo uma significativa expansão nas direções sul e noroeste. Para Lima (2015), a expansão para a região sul foi primordialmente influenciada pela ação do Estado, pois já existiam alguns equipamentos públicos como o Hospital Regional Doutor Cleodon Carlos de Andrade, implantado em 1990, e a Universidade Estadual do Rio Grande do Norte (UERN), 
criada em 1977; e, com a chegada de um último em 2010, que foi o Instituto Federal do Rio Grande do Norte (IFRN), ocorreu nova dinâmica no processo de expansão já decorrente das outras estruturas citadas. Salienta-se que essa expansão ao lado sul segue o alinhamento da BR 405, tendo um perfil linear.

Outro fator importante na atuação do Estado para a ocupação dessa região foram as linhas de créditos para financiamento da casa própria. Isso contribuiu para aceleração de abertura de loteamentos, que originaram o bairro Chico Cajá, situado na direção sul, objeto deste estudo, e uma forte especulação imobiliária, que aumentou o valor dos terrenos e imóveis nessa área, evidenciando assim o papel dos promotores imobiliários. Já na região noroeste, a autora aponta que a expansão da cidade foi orientada mediante preços mais acessíveis, visto que não houve maiores investimentos de infraestrutura que justificassem esse crescimento. A ocupação no sentido nordeste da cidade, onde se localiza o bairro São Geraldo, também recebeu influência da atuação do Estado primordialmente a partir da implantação da Universidade Federal Rural do Semi-Árido (UFERSA), associada à ação dos proprietários fundiários, dos promotores imobiliários e dos grupos sociais excluídos.

A atuação dos grupos sociais excluídos, por sua vez, pode ser visualizada na morfologia da cidade como um todo e também na formação dos bairros foco de estudo, o Chico Cajá e o São Geraldo.

\section{RESULTADOS E DISCUSSÕES}

Os bairros foco de estudo são o Chico Cajá e o São Geraldo, localizados em regiões distintas da cidade, ao sul e nordeste, respectivamente, conforme indicado da Figura 3, contudo, ambos em perímetros de expansão da cidade. Essas áreas apresentam dinâmicas urbanas diferenciadas e espelham a atuações de diversos produtores do espaço, o que ocasionou contradições em sua morfologia. Os limites dos bairros foram definidos com base em pesquisas realizadas pelo Programa Acesso à Terra Urbanizada 5 (2016), para fins de elaboração do Plano Diretor, instrumento que ainda se encontra em processo de elaboração. Para tanto, levou-se em consideração a área de potencial expansão do perímetro urbano.

\footnotetext{
${ }_{5}^{5}$ O Programa Acesso à Terra Urbanizada da Universidade Federal Rural do Semi-Árido, em parceria com os Ministérios da Educação das Cidades, atua em cidades do interior do Estado do Rio Grande do Norte promovendo a regularização fundiária de interesse social. Em Pau dos Ferros, além dessa atividade também desenvolve, juntamente com a Prefeitura Municipal, a elaboração do Plano Diretor Participativo, que teve início no ano de 2015 e ainda se encontra em processo de elaboração. Vale ressaltar que os autores dessa pesquisa fazem parte do programa, sendo Carla Caroline Alves Carvalho, integrante de corpo de alunos pesquisadores, e Almir Mariano de Sousa Junior, o coordenador.
} 
Figura 3 - Localização dos bairros São Geraldo e Chico Cajá

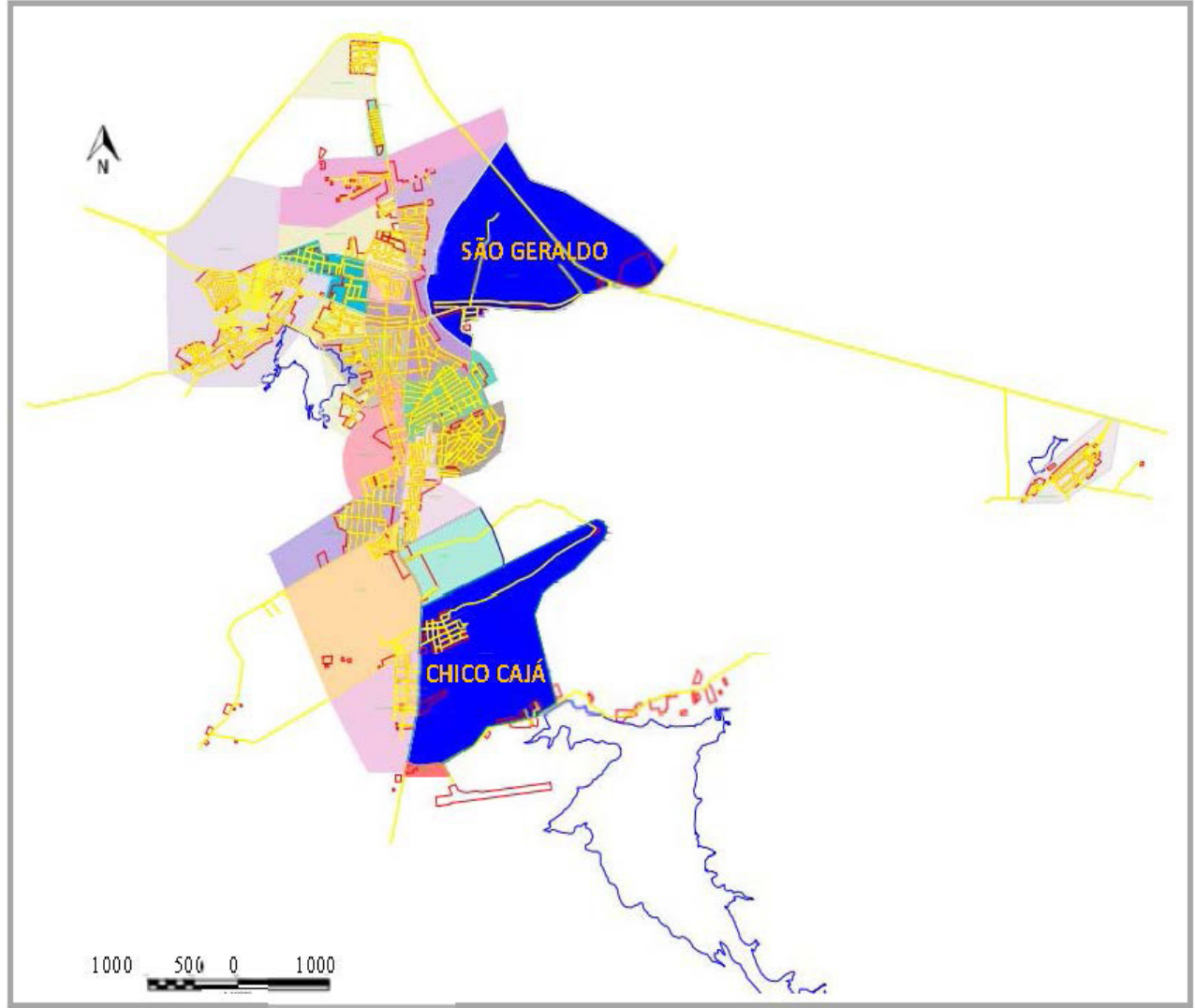

Fonte: Adaptado de Programa Acesso à Terra Urbanizada (2016)

O bairro Chico Cajá data de um período recente, visto que foi instituído pela Lei Municipal n. 812/2000, e vem passando por um acelerado processo de expansão urbana. Ao realizar um estudo acerca da expansão urbana do Chico Cajá entre os anos de 2007 a 2012, Maia e Silva (2013) verificaram que os motivos que impulsionaram os primeiros moradores a ocuparem o bairro foram os preços acessíveis, a tranquilidade e a melhor qualidade de vida, haja vista que, por não estar muito próximo ao centro da cidade, não possui grande fluxo de veículos, de pessoas e de mercadorias, que causam barulho, insegurança e poluição. Isso, é um dos fatores que contribuem para a ocupação de novas áreas nas cidades, fazendo com que áreas que antes eram prioritariamente rurais, passem a receber dinâmicas urbanas, configurando assim espaços de transição, como aponta Alegre (2016) ao estudar as áreas periurbanas.

Com o passar dos anos, outros fatores foram sendo agregados e modificados, devido à acentuada valorização imobiliária, fazendo com que aumentassem os preços dos imóveis e terrenos. Isso evidencia a contradição do valor de uso e do valor de troca evidenciada por Carlos (2015) ao analisar a produção do espaço urbano sob o viés da acumulação do capital.

Esse acentuado crescimento é notório na zona sul da cidade, onde o bairro Chico Cajá se localiza, expandido pela influência da implantação das instituições públicas ora referenciadas e atraindo olhares da especulação imobiliária, que empregam constantes processos de valorização de sua área. Associada a isso, está a atuação do Programa Minha Casa Minha Vida (PMCMV), que possibilitou o acesso ao financiamento da casa própria para um grande número de moradores do bairro em face da situação de regularidade fundiária dos lotes à venda no bairro, pois esse é um dos critérios para a conquista da linha de crédito pelo PMCMV. 
Tal contexto evidencia a atuação do Estado por meio da elaboração da política pública habitacional, executada por meio PMCMV. Maia e Silva (2013) indicam que, antes dessa intensificada ocupação, o que existia no bairro eram áreas à espera de valorização imobiliária, característico de áreas periurbanas e correspondente à lógica de acumulação do capital (ALVES; VALE, 2013). Isso pode ser verificado no processo de abertura de loteamentos no bairro, que contou com a atuação direta dos proprietários fundiários e os promotores imobiliários, conforme mostra a Tabela 1.

Tabela 1 - Abertura de loteamentos no bairro Chico Cajá

\begin{tabular}{l|c|c|c|c|c}
\hline \multicolumn{1}{c|}{ Loteamento } & Ano & Área Total $\left(\mathbf{m}^{\mathbf{2}}\right)$ & $\begin{array}{c}\text { Quantidade de } \\
\text { Quadras }\end{array}$ & $\begin{array}{c}\text { Quantidade de } \\
\text { Ruas }\end{array}$ & $\begin{array}{c}\text { Quantidade de } \\
\text { Lotes }\end{array}$ \\
\hline Colinas Zona Sul I & 2004 & 12800.63 & 2 & 1 & 43 \\
Colinas Zona Sul II & 2007 & 35195.5 & 6 & 4 & 100 \\
Pedra Azul & 2008 & 89613.68 & 9 & 8 & 179 \\
Planalto- I Etapa & 2009 & 17647.56 & 3 & 3 & 42 \\
Colinas Zona Sul III & 2009 & 11938.2 & 2 & 3 & 34 \\
Colinas Zona Sul IV & 2010 & 29292.79 & 11 & 6 & 68 \\
Planalto- II Etapa & 2012 & 15.230 .83 & 4 & 2 & 39 \\
Arizona & 2014 & 100000 & 6 & 6 & 138 \\
\hline
\end{tabular}

Fonte: Pau dos Ferros (2017).

O primeiro loteamento aberto foi o Colinas Zona Sul I no ano de 2004. Em momentos oportunos a posteriori, o proprietário da terra loteou outras áreas, gerando mais três etapas e hoje se constitui como a maior área ocupada do bairro. Os loteamentos Planalto, Pedra Azul e Arizona ainda não foram ocupados. Apesar de todos os lotes já estarem registrados na Secretaria de Tributação, o início de suas vendas ainda não ocorreu. O Loteamento Arizona, de acordo com a divisão dos bairros apresentada na Figura 2, está situado parte no bairro Chico Cajá e outra parte no Bairro Arizona. Assim, os dados utilizados nesta pesquisa correspondem à porção desse loteamento que está dentro do Chico Cajá. A Figura 4 mostra a espacialização desses empreendimentos no Chico Cajá. 
Figura 4 - Loteamentos no Chico Cajá

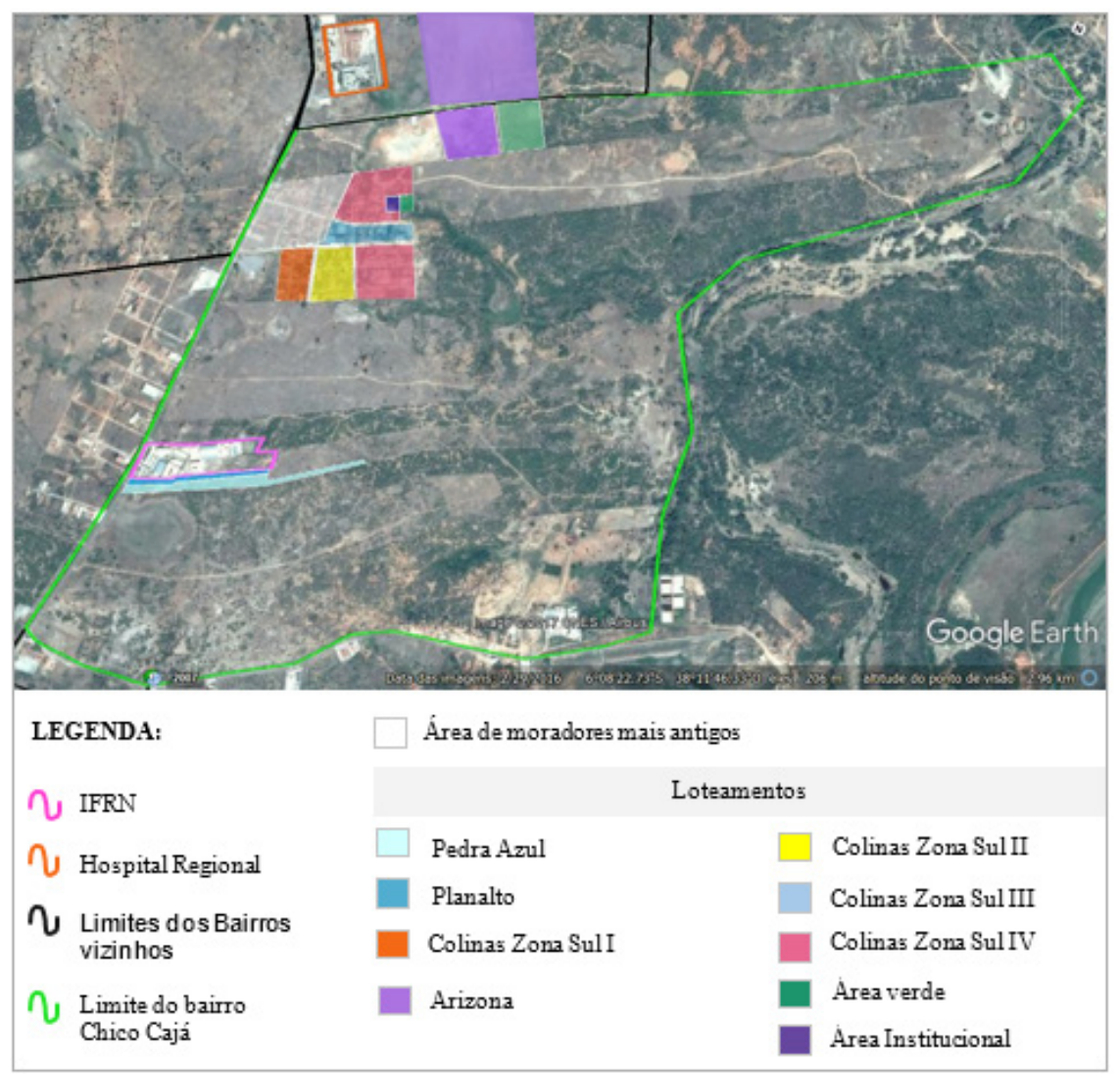

Fonte: Elaborada pelos autores (2017)

É válido ressaltar que, embora o município não possua ainda instrumentos de planejamento urbano, como o plano diretor, a regulação da ocupação do solo urbano, no que se refere à abertura de loteamentos e condomínios fechados, é feita com base nas leis federais de parcelamento do solo urbano, com ênfase na Lei 9.785/99 (BRASIL, 1999) e na Lei 6.766/79 (BRASIL, 1979). De acordo com documentos emitidos pela Secretaria Municipal de Meio Ambiente de Pau dos Ferros, seguem-se os seguintes critérios com relação à taxa de ocupação: deve ser reservado no mínimo 35\% da área total do projeto para uso público, sendo $20 \%$ para vias de circulação, $10 \%$ para áreas verdes e $5 \%$ para usos institucionais. A Tabela 02 mostra a destinação de áreas nos loteamentos do Chico Cajá:

Tabela 2 - Destinação de áreas nos loteamentos do Chico Cajá

\begin{tabular}{|c|c|c|c|c|c|c|c|c|}
\hline Loteamento & \begin{tabular}{|c|} 
Área \\
média dos \\
lotes $\left(\mathrm{m}^{2}\right)$
\end{tabular} & \begin{tabular}{|c|}
$\begin{array}{c}\text { Área Total } \\
\text { dos Lotes } \\
\left(\mathrm{m}^{2}\right)\end{array}$ \\
\end{tabular} & $\begin{array}{l}\text { Área das } \\
\text { Vias }\left(\mathrm{m}^{2}\right)\end{array}$ & Taxa (\%) & $\begin{array}{c}\text { Área } \\
\text { Verde } \\
\left(\mathrm{m}^{2}\right) \\
\end{array}$ & $\begin{array}{c}\text { Taxa } \\
\text { (\%) }\end{array}$ & \begin{tabular}{|c|} 
Área \\
Institucional \\
$\left(\mathrm{m}^{2}\right)$ \\
\end{tabular} & $\begin{array}{l}\text { Taxa } \\
\text { (\%) }\end{array}$ \\
\hline Planalto - Et. I & 237.27 & 10338.09 & 4508.45 & 25.55 & 1250 & 7.08 & 1250 & 7.08 \\
\hline Planalto - Et. II & 221.32 & 8894.08 & 4036.75 & 26.50 & 1530 & 10.04 & 770 & 5.05 \\
\hline Col. Zona Sul I & 259.65 & 11120.63 & 1680 & 13.12 & 0 & 0 & 0 & 0 \\
\hline Col. Zona Sul II & 254.22 & 25422.5 & 11130.66 & 31.63 & 0 & 0 & 0 & 0 \\
\hline Col. Zona Sul III & 272.51 & 9279.4 & 2658.8 & 22.27 & 0 & 0 & 0 & 0 \\
\hline Col. Zona Sul IV & 260.11 & 17687.7 & 7320.09 & 24.99 & 2205 & 7.53 & 2080 & 7.1 \\
\hline Pedra Azul & 396.87 & 71326.53 & 18287.15 & 20.41 & 0 & 0 & 0 & 0 \\
\hline Arizona & 190.14 & 26239.68 & 22337.8 & 22.34 & 10487 & 10.48 & 4652.33 & 4.65 \\
\hline
\end{tabular}

Fonte: Pau dos Ferros (2017). 
Percebe-se que, no tocante à destinação de área para vias públicas, apenas o loteamento Colinas Zona Sul I não atingiu a taxa mínima de $20 \%$. Já no tocante à destinação de área verde e institucional, apenas o Colinas Zona Sul IV determinou essa taxa territorial, que tentou englobar as demais etapas em um único registro junto à Secretaria de Tributação. Situação adversa se deu para o loteamento Planalto, que foi registrado em duas etapas, porém está contida na segunda a primeira etapa. Nesse segundo momento, o Planalto já atinge todos os índices de reserva de áreas.

No caso do loteamento Arizona, o mais recentemente implantado (2014), são contempladas todas as taxas territoriais de áreas públicas; na parte localizada bairro Chico Cajá, está contida sua área verde, conforme mostram a Figura 4 e a Tabela 2. É importante observar, ainda, que este foi o único que evidenciou em projeto a destinação de áreas para calçadas, mostrando que, com o passar dos anos, o ordenamento desses empreendimentos adotaram maior rigor em sua elaboração. Esse maior rigor é exigido prioritariamente pelo Estado, pois, de acordo com Moraes (2005), ele se constitui o principal agente do espaço e é responsável por criar as normas e leis que regulamentam o uso e ocupação do solo. Já o loteamento Pedra Azul, em projeto, não destinou áreas verdes nem institucionais, evidenciando a dificuldade de fiscalização da gestão municipal no que diz respeito ao cadastro e consolidação via órgãos públicos dos loteamentos. Todos esses critérios são de suma importância para o estabelecimento de uma morfologia urbana mais organizada, visto que o bairro apresenta quadras bem definidas, ruas largas, se comparadas com áreas mais antigas da cidade, entre outros fatores. Além disso, contribuem para o crescimento da especulação imobiliária, que constantemente aumenta os valores de terrenos e imóveis, implicando diretamente no público que pode ter acesso a esse espaço.

Apesar de ter uma expansão acelerada, a infraestrutura urbanística do bairro não acompanhou no mesmo ritmo, pois ainda existem ruas sem calçamento, pontos de pouca iluminação pública, ausência de esgotamento sanitário, destinação inadequada dos resíduos das obras, entre outros problemas. Isso implica no direito à cidade, visto que a falta de infraestrutura segrega essa população do acesso a moradia em um ambiente seguro, saudável e que permita uma boa qualidade de vida. Corrêa (1989), ao estudar a produção do espaço urbano, ressalta que essa realidade é produzida na ação dos agentes sociais e simboliza uma maneira de segregação e sobrevivência mediante as condições impostas. Outro fator que deve ser observado é que o Chico Cajá apresenta muitos contrastes intrínsecos de áreas periurbanas, pois, como mostra a Figura 5 , coexistem nessa localidade atividades que são inerentes à vida urbana e à rural, podendo-se encontrar desde a construção de residenciais fechados até uma fazenda, a Fazenda Chico Cajá, de onde foram desmembradas as terras para os loteamentos que deram origem ao bairro.

Figura 5 - contrastes entre o urbano e rural no bairro Chico Cajá

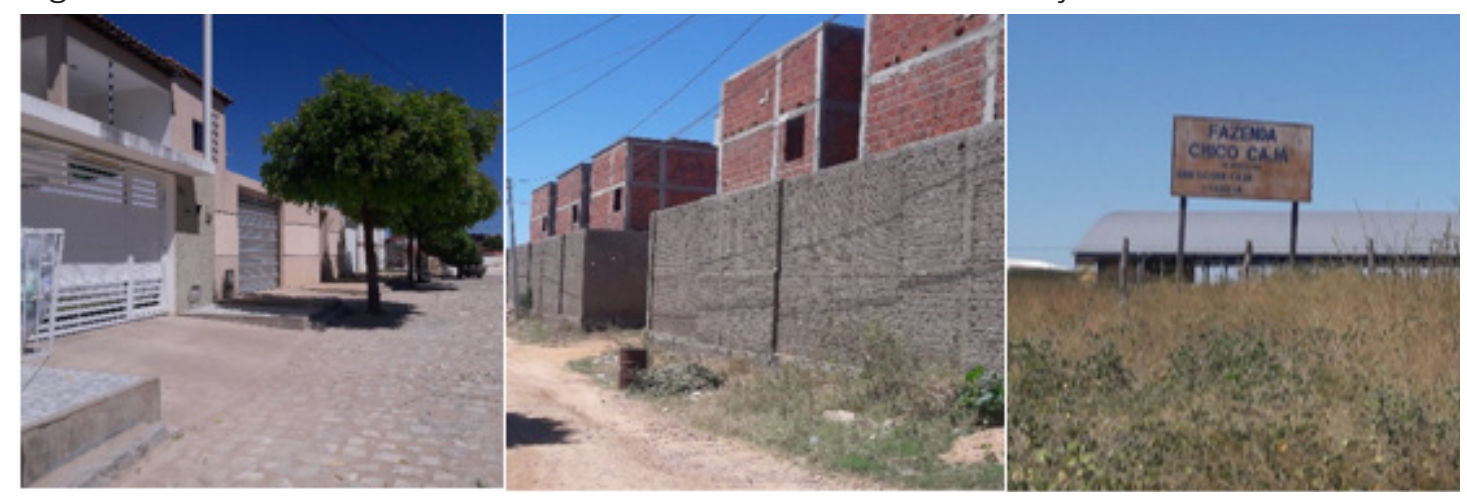

Fonte: Elaborada pelos autores (2017). 
Situações de contraste também são observadas no bairro São Geraldo, o qual é um dos mais antigos da cidade de Pau dos Ferros, e está separado do centro e dos demais bairros por meio do rio Apodi-Mossoró. Essa localidade tem sofrido modificações intensas em sua dinâmica urbana, influenciada por muitos fatores, dentre eles pode-se destacar primordialmente a instalação da Universidade Federal Rural do Semiárido (UFERSA). Essa instituição foi instalada em um período muito próximo ao da implantação do IFRN no Chico Cajá, em 2010, porém, diferentemente desse bairro, o São Geraldo não teve uma expansão urbana tão consolidada quanto a vivenciada pelo outro bairro em estudo.

Bezerra e Lima (2011), ao estudarem a segregação socioespacial na cidade de Pau dos Ferros, observam que, no São Geraldo, existem pontos que não favorecem a atratividade do mercado imobiliário, como as escassas amenidades naturais ${ }^{6}$ e por se tratar de uma área ocupada tradicionalmente por uma população pobre. Soma-se a isso a dificuldade de acessibilidade ao bairro, pois grande parte da ocupação desse bairro se deu ao longo da RN-177, uma rodovia muito estreita, sem acostamento e vinculada a uma expansão urbana que não respeitou limites mínimos de distanciamento da rodovia, como mostra o primeiro cenário da Figura 6:

\section{Figura 6 - Cenários do bairro São Geraldo}

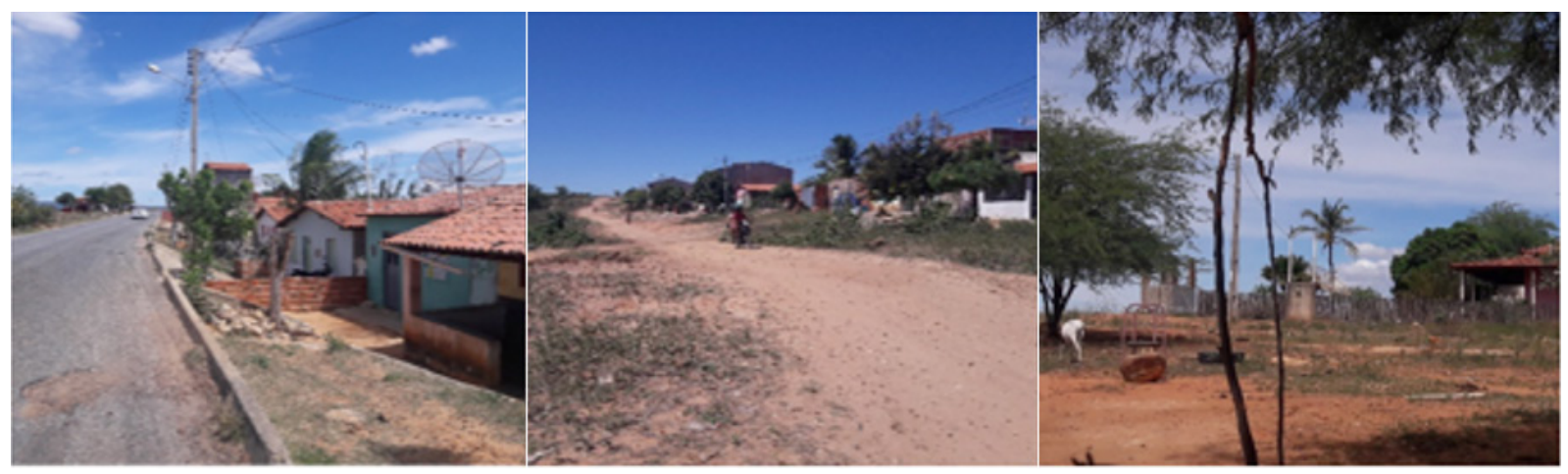

Fonte: Elaborada pelos autores (2017).

Os cenários apontados pela Figura 6 evidenciam ainda uma extrema carência de infraestruturas e predominância de casas de baixo padrão arquitetônico, além do convívio simultâneo com atividades rurais dentro do perímetro urbano. Esse último fator muito se assemelha ao bairro Chico Cajá, como fora evidenciado.

Porém, à medida que surgem novos equipamentos públicos, como a instalação da UFERSA, aumenta-se a atuação e articulam-se demais agentes produtores do espaço urbano, como mecanismo de conjuntamente criarem novos processos de valorização de uma específica área. Como exemplo disso, ocorreu a finalização das obras da BR 226 (2013), especificamente no trecho de contorno ao perímetro urbano de Pau dos Ferros, o que contribuiu sobremaneira na atração de novos investimentos do setor privado, materializados por meio do loteamento Boa Vista e do condomínio fechado Village Boulevard, os quais estão situados de acordo com o exposto pela Figura 7. Todos esses fatores refletem a ação do Estado se reverberando sobre a promoção imobiliária do bairro.

\footnotetext{
${ }^{6}$ As amenidades naturais são o conjunto de características físicas que contribuem para a valorização de uma determinada área, como a proximidade com mar, lagoa, sol, verde e entre outras. Elas tornam essa localidade mais atrativa para os investimentos imobiliários, os quais, associados a campanhas publicitárias, exaltando essas qualidades, acabam por aumentar o preço de seus terrenos e imóveis (CORRÊA, 1989).
} 
Figura 7 - Ocupação do Bairro São Geraldo

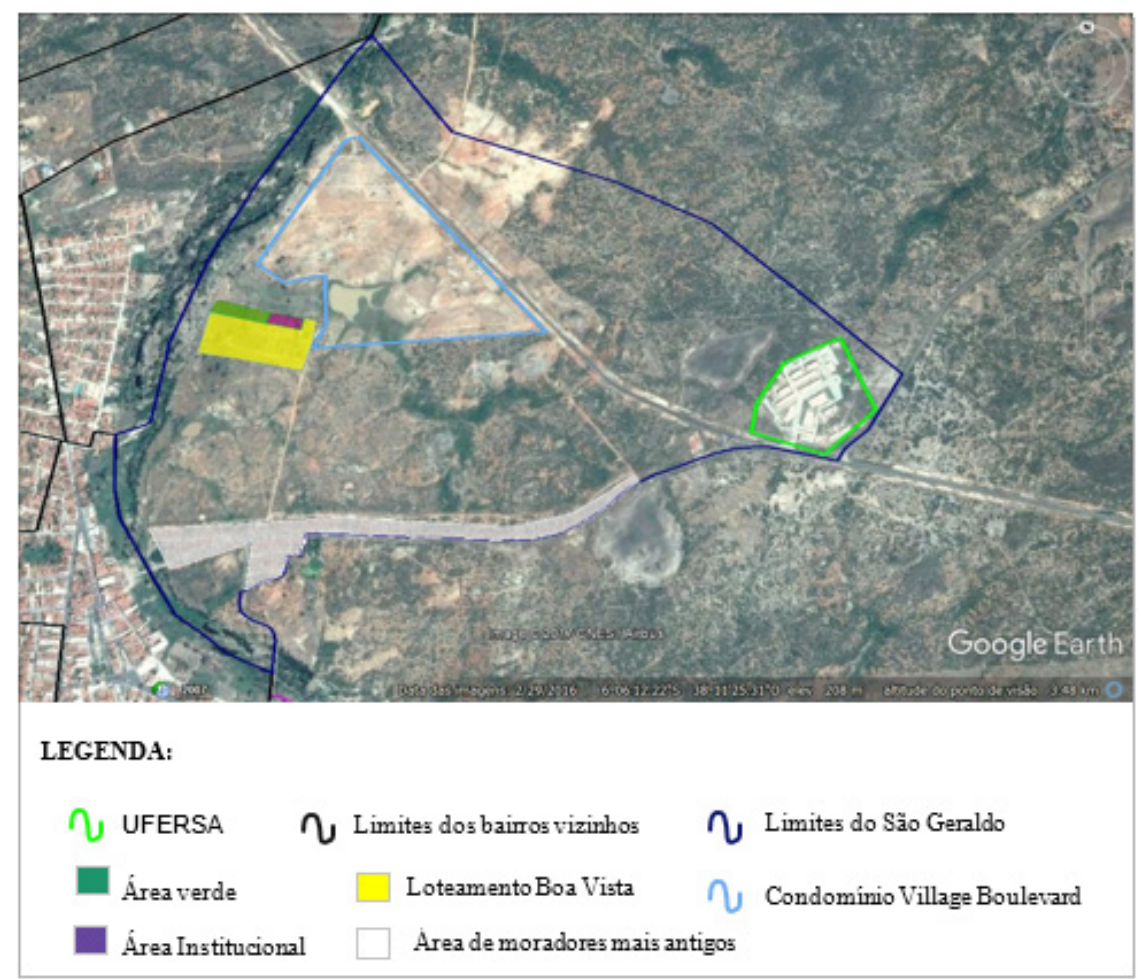

Fonte: Elaborada pelos autores (2017).

A Figura 7 mostra que os novos empreendimentos imobiliários do bairro estão próximos um do outro e distanciados da área de ocupação mais antiga do bairro, de modo a acentuarem alguns fatores: o espraiamento da cidade; a conformidade de tecidos urbanos vazios, bem como a segregação socioespacial de uma antiga área pobre e uma nova área socioeconomicamente mais privilegiada. Acerca disso Sposito e Góes (2013), ressaltam que atualmente a expansão territorial acontece de maneira muito seletiva socialmente, mostrando assim que existe uma nova articulação entre a divisão econômica e a divisão social.

O condomínio Village Boulevard evidenciado na Figura 7 é um espaço fechado que teve o projeto de vendas de lotes lançado em 2011. Propôs um novo padrão de habitabilidade para a cidade de Pau dos Ferros, atendendo ao ideário de bem-estar e lazer em estruturas de alto padrão arquitetônico e ambiente condominial horizontal fechado. Os muros que o cercam bem como o sistema de segurança são elementos que redefinem a relação de seus moradores com o restante da cidade.

De acordo com a pesquisa de Santos e Alves (2015), no referido ano já haviam sido vendidos cerca de $75 \%$ dos seus 401 lotes. Porém, até o presente momento, ainda não se deu o início da ocupação desse espaço. Isso pode estar associado ao fato de o condomínio encontrar-se em situação de irregularidade fundiária urbana. Tal fato se contrasta com a realidade vivenciada no Chico Cajá, que possui predominantemente loteamentos abertos, com padrões de infraestrutura bem inferior ao oferecido pelo Village Boulevard, porém, por estarem regulares fundiariamente e serem mais acessíveis financeiramente, isso facilitou a sua ocupação.

Situação semelhante a essa acontece com o loteamento Boa Vista, localizado vizinho ao condomínio Village Boulevard, e já tem alguns imóveis construídos em seus lotes. A Tabela 3 reúne algumas informações acerca desse empreendimento: 
Tabela 3 - Loteamento Boa Vista

\begin{tabular}{c|c}
\hline Loteamento & Boa Vista \\
\hline Ano & 2013 \\
\hline Área Total & 52736.5 \\
\hline Quantidade de Quadras & 6 \\
\hline Quantidade de Ruas & 4 \\
\hline Quantidade de Lotes & 96 \\
\hline Área média dos lotes & $355.93 \mathrm{~m}^{2}$ \\
\hline Área Total dos Lotes & $33450 \mathrm{~m}^{2}$ \\
\hline Área das Vias & $10886.5 \mathrm{~m}^{2}(20.64 \%)$ \\
\hline Área Verde & $56000 \mathrm{~m}^{2}(10.62 \%)$ \\
\hline Área Institucional & $2800 \mathrm{~m}^{2}(5.31 \%)$ \\
\hline
\end{tabular}

Fonte: Pau dos Ferros (2017).

É possível notar que esse loteamento está de acordo com os critérios de parcelamento do solo analisados pela prefeitura, já que faz a correta destinação para áreas públicas (verdes, institucionais e vias). É importante ressaltar ainda que tanto o loteamento Boa Vista, quanto o Boullevard, foram implantados mais recentemente que a maioria, daqueles localizados no Chico Cajá, dos quais cerca de 75\% foram estabelecidos entre 2004 e 2010. Isso evidencia que, no bairro São Geraldo, as tendências de valorização imobiliária são mais tardias do que as do outro bairro.

Além disso, no intuito de uma melhor percepção comparativa entre os dois bairros, foi realizado um levantamento acerca de suas características gerais junto aos cadastros imobiliários disponibilizados pela Secretaria Municipal de Tributação, os quais estão elencados na Tabela 4.

Tabela 4 - comparativo entre o bairro São Geraldo e Chico Cajá

\begin{tabular}{|c|c|c|c|c|c|c|c|c|}
\hline Bairro & Ruas & Lotes & $\begin{array}{c}\text { Área } \\
\text { Média dos } \\
\text { Lotes }\left(\mathrm{m}^{2}\right)\end{array}$ & $\begin{array}{c}\text { Área Média } \\
\text { Construída } \\
\left(\mathrm{m}^{2}\right)\end{array}$ & $\begin{array}{l}\text { Lotes } \\
\text { ocupados }\end{array}$ & $\begin{array}{c}\text { Terrenos } \\
\text { Vazios }\end{array}$ & $\begin{array}{l}\text { Valor Venal } \\
\text { médio dos } \\
\text { Imóveis (R\$) }\end{array}$ & $\begin{array}{l}\text { Valor Venal } \\
\text { médio dos } \\
\text { Terrenos (R\$) }\end{array}$ \\
\hline Chico Cajá & 12 & 376 & 251.80 & 117.91 & 229 & 147 & 67009.52 & 12776.65 \\
\hline São Geraldo & 10 & 474 & 159.92 & 63.05 & 417 & 57 & 33160.20 & 196685.3 \\
\hline
\end{tabular}

Fonte: Pau dos Ferros (2017).

Os dados mostrados pela Tabela 4 foram coletados a partir dos cadastros de cada rua pesquisada, porém essa quantidade de ruas não corresponde ao número total já cadastradas, visto que muitas delas ainda não foram nomeadas, constando apenas como "rua projetada", o que dificulta a sua catalogação em virtude das limitações encontradas pelo sistema de buscas do cadastro imobiliário do município. Assim, foram levantadas somente as que já receberam nomenclatura.

Mediante a leitura da Tabela 4, é possível notar ainda que existe uma maior densidade de ocupação no São Geraldo, visto que, em uma quantidade inferior de ruas pesquisadas, há praticamente o dobro de lotes ocupados e cerca de um terço dos terrenos vazios quando comparados com o Chico Cajá. Além disso, os lotes do São Geraldo possuem uma área média inferior aos do outro bairro, o que favorece essa maior ocupação em detrimento de um menor espaço.

Quando analisados interiormente, pode-se notar que a área média dos lotes localizados no loteamento Boa Vista do São Geraldo $\left(355.93 \mathrm{~m}^{2}\right)$ é superior à área média dos lotes do bairro 
como um todo (159.92 $\mathrm{m}^{2}$ ), ou seja, é cerca de duas vezes maior que as unidades comumente encontradas nessa localidade. Enquanto isso, no Chico Cajá, não há praticamente diferença entre essas áreas, visto que a área média das unidades de terreno dos loteamentos investigados é de $279.03 \mathrm{~m}^{2}$, e a área média do bairro como um todo é de $251.8 \mathrm{~m}^{2}$, isso se justifica quando se nota que os loteamentos correspondem à maior área ocupada do bairro, já contribuindo significativamente para o resultado da média total. Maiores terrenos são característicos de áreas periféricas e se tornam fatores atrativos para a ocupação (DEMATTEIS, 2015).

No que se refere à valorização imobiliária presente nos bairros, foi tomado como base o valor venal instituído mediante o Código Tributário do município, para fins de cobrança de impostos. Assim, no tocante ao valor venal dos imóveis, o Chico Cajá apresenta um valor médio estimado de aproximadamente o dobro do valor médio do São Geraldo, isso pode ser justificado majoritariamente pela maior área construída das unidades, atrelado ao maior padrão arquitetônico das residências empregado do primeiro bairro. Isso reflete sobre o espaço enquanto mercadoria na produção da cidade (CARLOS, 2015), sendo que alguns espaços recebem maiores investimentos, recursos e infraestrutura, passando a ser mais valorizados do que outros, como é o caso do Chico Cajá em relação ao São Geraldo.

Enquanto isso, o valor venal médio dos terrenos situados no Chico Cajá é muito inferior aos do São Geraldo, essa contradição pode ser justificada em virtude do fato de que a grande maioria dos terrenos vazios deste estão situados no loteamento Boa Vista, que, além de estar situado em uma área de especulação imobiliária, apresenta lotes com área média de $355.93 \mathrm{~m}^{2}$, que é muito superior à média dos lotes do bairro como um todo, que é de $159.92 \mathrm{~m}^{2}$.

Logo, pode-se notar que, apesar das diferenciações de morfologia física e social notadas entre os bairros estudados, ambos situados em diferentes zonas de expansão urbana, sofrem intensas transformações em seu espaço, que modificam a sua funcionalidade mediante a articulação e interesses dos diferentes agentes sociais. Tal movimento se expressa a partir da conjunção de suas estratégias que estão condicionadas à produção capitalista e, por isso, integram novos espaço à lógica de acumulação.

\section{CONSIDERAÇÕES FINAIS}

Pode-se notar que o estabelecimento da morfologia urbana dos bairros foco de estudo é fruto primordialmente das ações articuladas entre o Estado, juntamente com os promotores imobiliários, que promovem a especulação imobiliária, e os grupos sociais excluídos. Porém o processo de formação do bairro São Geraldo é diferente daquele vivenciado pelo Chico Cajá o que implica diretamente no estabelecimento dos padrões de ocupação.

Isso porque, conforme discutido, o primeiro bairro passou por um forte processo de valorização imobiliária que esteve associado a outros elementos que favoreceram esse contexto, como a acessibilidade, proximidade a pontos estratégicos como o IFRN, a UERN e o Hospital Regional, bem como a própria inserção em uma região de alta expansão urbana da cidade. Por sua vez, o São Geraldo, apesar de ter recebido um elemento potencializador de sua ocupação, a UFERSA, não vivenciou uma especulação imobiliária tão acelerada quanto à do Chico Cajá, pois, apesar de estar localizado muito próximo ao centro da cidade, não possui boas condições de acessibilidade. Além disso, o maior investimento imobiliário feito nessa localidade trata-se de um condomínio residencial fechado, o Village Boulevard, de alto padrão econômico, o que 
torna os terrenos menos acessíveis financeiramente. Apesar disso, já obteve uma significativa parcela de vendas, porém ainda não foi realizada a ocupação desse condomínio em virtude da sua situação de irregularidade fundiária. Tal contexto é diferente do Chico Cajá, que recebeu primordialmente loteamentos abertos, com padrões econômicos e de infraestrutura muito inferiores ao do condomínio Village Boulevard, porém, como se encontravam em situação de regularidade fundiária, foram ocupados com mais rapidez. Logo, observou-se que a valorização fundiária se deu de maneira diferenciada para esses espaços e contribuiu para a formação de segregação socioespacial ao longo do tecido urbano. É este um movimento comum às demais cidades brasileiras, haja vista a vivência do da lógica de produção capitalista ao qual estão submetidas.

\section{REFERÊNCIAS}

ABELLÁN, Francisco Cebrián. Manifestaciones de la dispersión urbana en el entorno de las ciudades medias. Respuestas convergentes en contextos diferentes. Cidades, São Paulo, v. 12, n. 21, p. 55-90, 2015.

ALEGRE, Silvina. Configuraciones territoriales en el periurbano del partido de Florencio Varela. Mundo Agrario, Buenos Aires, v. 17, n. 34, abr. 2016.

ALVES, Flamarion Dutra; VALE, Ana Rute. A relação campo-cidade e suas leituras no espaço. ACTA Geográfica, Boa Vista, RR, p. 33-41, 2013. (Ed. Esp. Geografia Agrária).

BEZERRA, Josué Alencar; LIMA, Keliane Queiroz de. Desigualdades socioespaciais em pequenas cidades: a segregação residencial na cidade de Pau dos Ferros-RN. Revista Geotemas, Pau dos Ferros, RN, v. 1, n. 1, p. 43-54, 2011.

BRASIL. Lei n. 9.785, de janeiro de 1999. Altera o Decreto-Lei n. 3.365, de 21 de junho de 1941 (desapropriação por utilidade pública) e as Leis n. 6.015, de 31 de dezembro de 1973 (registros públicos) e 6.766, de 19 de dezembro de 1979 (parcelamento do solo urbano). Brasília, 1999. Disponível em: http:// www.planalto.gov.br/ccivil_03/LEIS/L9785.htm. Acesso em: 2 jul. 2019.

BRASIL. Lei n. 6.776, de dezembro de 1979. Dispõe sobre o Parcelamento do Solo Urbano e dá outras Providências. Brasília, 1979. Disponível em: http://www.planalto.gov.br/ccivil_03/LEIS/L6766.htm. Acesso em: 2 jul. 2019.

CARLOS, Ana Fani Alessandri (Ed.). Crise urbana. São Paulo: Contexto, 2015.

CORRÊA, Roberto Lobato. O espaço urbano. 3. ed. São Paulo: Ática, 1989.

DANTAS, Joseney Rodrigues de Queiroz. As cidades medias no desenvolvimento regional: um estudo sobre Pau dos Ferros (RN). 2014. 261f. Orientadora: Maria do Livramento Miranda Clementino. Tese (Doutorado em Desenvolvimento Regional, Cultura e Representações) - Universidade Federal do Rio Grande do Norte, Natal, 2014.

DEMATTEIS, Giuseppe. Contraurbanização, periurbanização, cidade dispersa e rede de cidades na Itália. Cidades, São Paulo, v. 12, n. 21, p. 14-34, 2015.

HARVEY, David. A liberdade da cidade. In: VAINER, Carlos et al. Cidades rebeldes: passe livre e as manifestações que tomaram as ruas do Brasil. São Paulo: Boitempo/Carta Maior, 2013. p. 47-61.

INSTITUTO BRASILEIRO DE GEOGRAFIA E ESTATÍSTICA (IBGE). Censo Demográfico 2010. Rio de Janeiro: IBGE, 2010. 
LIMA, Harrana Ávilla Carneiro de. Expansão urbana sobre Pau dos Ferros: um olhar sobre o desenvolvimento socioespacial. 2015. 61f. Trabalho de Conclusão de Curso (Graduação em Ciência e Tecnologia) Universidade Federal Rural do Semiárido, Pau dos Ferros, 2015.

MAIA, Andréa Paula Rego; SILVA, Cícero Nilton Moreira da. Expansão urbana no espaço pauferrense a partir da análise do bairro Chico Cajá de 2007 a 2012. Revista Geotemas, Pau dos Ferros, RN, v. 3, n. 2, p. 75-90, 2013.

MARICATO, Ermínia et al. Cidades rebeldes: passe livre e as manifestações que tomaram as ruas do Brasil. 1. ed. São Paulo: Boitempo/Carta Maior, 2013.

MORAES, Antonio Carlos Robert. Ordenamento territorial: uma conceituação para o planejamento estratégico. In: OFICINA SOBRE A POLÍTICA NACIONAL DE ORDENAMENTO TERRITORIAL: Para pensar uma política nacional de ordenamento territorial. Brasília, 13-14 nov. 2003. Anais [...]. Brasília: Ministério da Integração Nacional/Secretaria de Políticas de Desenvolvimento Regional, 2005. p. 43-7.

PAU DOS FERROS, Município [de]. Secretaria Municipal de Tributação de Pau dos Ferros. Relação dos imóveis por logradouro. Pau dos Ferros, RN, 2017.

PAU DOS FERROS, Município [de]. Lei Complementar 05/2010. Aprova o Código Tributário de Pau dos Ferros e dá outras providências. Pau dos Ferros, RN, Brasil, 2010. Disponível em: https://paudosferros. rn.gov.br/arquivos/168/LEIS_LC\%2005_2010_0000001.pdf. Acesso em: 2 jul. 2019.

PROGRAMA ACESSO À TERRA URBANIZADA. Plano Diretor Participativo - mapa das vias e bairros. Pau dos Ferros, RN: Universidade Federal Rural do Semiárido, 2016.

SANTOS, Antonio Carlos; ALVES, Larissa da Silva Ferreira. Produção do espaço urbano da cidade de Pau dos Ferros-RN: análise da tendência de valorização fundiária do bairro São Geraldo. Boletim de Geografia, Maringá, PR, v. 33, n. 2, p. 73-88, maio/ago. 2015.

SPOSITO, Maria Encarnação Beltrão; GÓES, Eda Maria. Espaços fechados e cidades: insegurança urbana e fragmentação socioespacial. São Paulo: Unesp, 2013.

\section{Sobre autores:}

Carla Caroline Alves Carvalho - Mestranda no Programa de Pós-Graduação em Planejamento e Dinâmicas Territoriais no Semiárido da Universidade Estadual do Rio Grande do Norte (UERN), Campus Pau dos Ferros. Bacharel em Ciência e Tecnologia na Universidade Federal Rural do Semi-Árido (UFERSA), Campus Pau dos Ferros. E-mail: carvcarolc@gmail.com, Orcid: http:// orcid.org/0000-0002-8233-7883

Larissa da Silva Ferreira Alves - Doutora em Geografia pela Universidade Federal do Ceará. Professora Adjunta do Departamento de Geografia e Coordenadora do Programa de PósGraduação em Planejamento e Dinâmicas Territoriais no Semiárido, da Universidade Estadual do Rio Grande do Norte (UERN), Campus de Pau dos Ferros. E-mail: larissa0185@gmail.com, Orcid: http://orcid.org/0000-0003-2232-9539

Almir Mariano de Sousa Junior - Doutor em Ciência e Engenharia de Petróleo pela Universidade Federal do Rio Grande do Norte (UFRN). Professor Efetivo da Universidade Federal Rural do Semi-Árido (UFERSA). Professor do Mestrado Acadêmico em Planejamento e Dinâmicas Territoriais 
da Universidade Estadual do Rio Grande do Norte (UERN).E-mail: almir.mariano@ufersa.edu.br, Orcid: http://orcid.org/0000-0002-3151-3832

Francisco do O. de Lima Junior: Doutor em Desenvolvimento Econômico pelo Instituto de Economia da Universidade Estadual de Campinas (UNICAMP). Desempenha o papel de Vice-reitor da Universidade Regional do Cariri (URCA). Professor Associado do Departamento de Economia da URCA. E-mail: limajunioreconoia@gmail.com, Orcid: http://orcid.org/0000-0002-6049-3893 